\title{
Especie nueva de Triumfetta (Tiliaceae) en el bosque mesófilo de montaña de Oaxaca, México
}

\section{New species of Triumfetta (Tiliaceae) in the cloud forest of Oaxaca, Mexico}

\author{
Martha Gual-Díaz ${ }^{1}$ y Fernando Chiang ${ }^{2}$ \\ ${ }^{l}$ Comisión Nacional para el Conocimiento y Uso de la Biodiversidad (CONABIO). Avenida Liga Periférico-Insurgentes Sur 4903, Col. Parques del \\ Pedregal, Delegación Tlalpan 14010 México, D. F., México. \\ ${ }^{2}$ Departamento de Botánica, Instituto de Biología, Universidad Nacional Autónoma de México. Apartado postal 70-367, 04510 México, D. F., México. \\ \mgual@conabio.gob.mx
}

\begin{abstract}
Resumen. Con base en el estudio de ejemplares de la familia Tiliaceae depositados en el herbario MEXU, se describe e ilustra una nueva especie de Triumfetta del bosque mesófilo de montaña de Oaxaca, México. Se discute su relación morfológica con T. coriacea Hochr. y con T. cucullata Fernald.

Palabras clave: Oaxaca, Triumfetta martinezalfaroi sp. nov., México.

Abstract. Based on the study of specimens of the family Tiliaceae deposited in MEXU, a new species of Triumfetta from the cloud forests of Oaxaca, Mexico is described and illustrated. Its morphological relationship with T. coriacea Hochr. and T. cucullata Fernald is discussed.
\end{abstract}

Key words: Oaxaca, Triumfetta martinezalfaroi sp. nov., Mexico.

\section{Introducción}

En 1703, el género Triumfetta L. fue propuesto por Plumier en honor a John Baptiste Triumfetti (1656-1708), médico italiano, catedrático en botánica y director del Jardín Botánico de Roma. En 1753, Linneo realiza la primera descripción completa del género, basado en la única especie conocida entonces, T. lappula L. (especie tipo).

De acuerdo con Heywood (1993), Cronquist (1981), Lay (1950) y Mabberley (2008), existen aproximadamente 150 especies de Triumfetta en los trópicos del mundo. Lay (1950) comenta que la mayoría de las especies están distribuidas en América, desde Estados Unidos (Florida), México, Centroamérica, hasta Argentina. Según Fryxell (1998), el neotrópico cuenta con 49 especies y de acuerdo con Lay (1950), la mayoría de las especies neotropicales se encuentran en México; algunas de ellas extienden su distribución hasta Centroamérica. En el país se han registrado 35 especies; con esta adición, se reconocen alrededor de 18 para el estado de Oaxaca (Gual, 2011).

Como resultado de la revisión de los ejemplares de la familia Tiliaceae para el proyecto "Biodiversidad de Oaxaca", resguardados en el Herbario Nacional de México

Recibido: 18 enero 2011; aceptado: 04 abril 2011
(MEXU), así como de la literatura pertinente y el apoyo en los tipos depositados en los herbarios MICH, MO y NY, se detectaron 3 ejemplares del género Triumfetta cuyas características morfológicas difieren de las especies ya descritas con anterioridad, concluyendo que pertenecen a una especie no descrita y se propone como integrante nueva del género.

Triumfetta martinezalfaroi Gual et F. Chiang, sp. nov. Fig. 1. Tipo: México: Oaxaca: municipio de Totontepec: Totontepec $\left(17^{\circ} 15^{\prime} \mathrm{N}, 96^{\circ} 02^{\prime} \mathrm{O}\right), 1900 \mathrm{~m}$ snm, bosque mesófilo de montaña, 21 agosto 1990, J. Riviera R. y G. J. Martin 1618 (Holotipo MEXU).

T. coriaceae Hochr. et T. cucullatae Fernald affinis, sed differt sepalis filiformibus appendicibus ca. $2 \mathrm{~mm}$, petalis spathulatis, stigma trifido, capsula triloculari ca. 80 spinulis obtecta, et lamina ad apicem acuminata, ad basem cordata.

Arbustos de 0.6 a $3.0 \mathrm{~m}$ de alto. Tallo glabrescente; ramas estrellado-pubescentes, glabrescentes con la edad. Hojas con lámina entera o ligeramente trilobada, ovada, 2.5$8.0 \mathrm{~cm}$ de largo, 1.0-4.0 $\mathrm{cm}$ de ancho, 5(-7)-nervadas, el haz estrellado-pubescente, con mayor densidad sobre las nervaduras, los pelos estrellados de 2 a 5 brazos, de consistencia áspera, el envés densamente estrellado- 


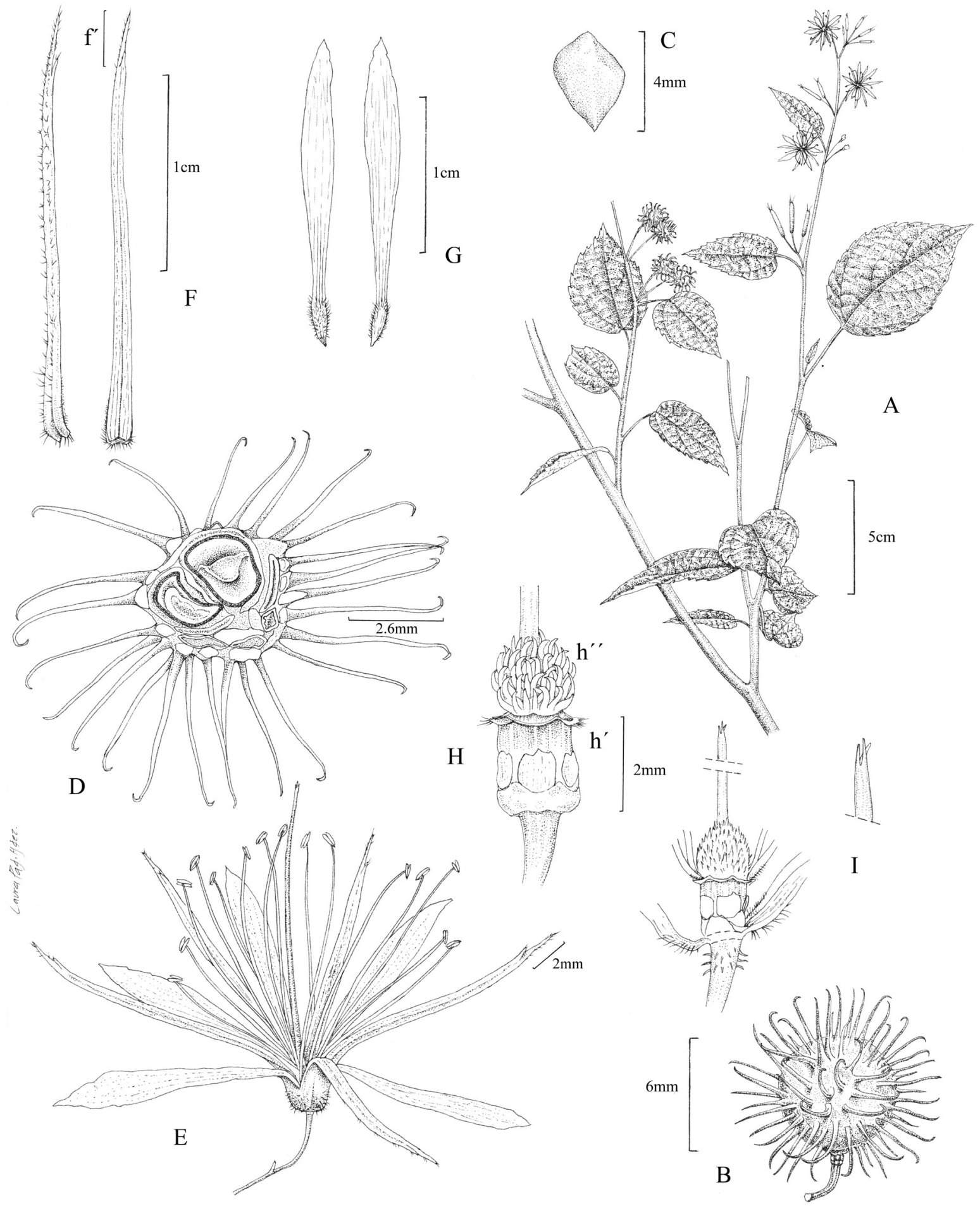

Figura 1. Triumfetta martinezalfaroi sp. nov.: A, rama con hojas, flores y frutos; B, fruto en vista lateral; C, semilla ; D, corte transversal del fruto mostrando las semillas; E, flor; F, sepálos vistas lateral y adaxial, f', apéndice; G, pétalos vista abaxial y adaxial; H, h', androginóforo, h"', anillo; I, vista lateral del androginóforo, anillo, ovario, estilo y estigma (basado en J. Riviera y G. J. Martin, 1618). 
pubescente, de consistencia suave, el ápice acuminado, el margen dentado-mucronado, con los primeros 4 pares de dientes basales glandulares, la base cordada; pecíolos de 1.0-1.8 cm de largo, densamente estrelladopubescentes. Inflorescencia en dicasios compuestos, axilares o terminales; pedúnculos y pedicelos ca. $1.0 \mathrm{~cm}$ de largo. Flores hermafroditas, ca. $2.7 \mathrm{~cm}$ de largo; cáliz con 5 sépalos filiformes, de $2.0-2.2 \mathrm{~cm}$ de largo, con pubescencia de pelos estrellados (de 2 a 4 brazos), el ápice acuminado con apéndice ca. $2.0 \mathrm{~mm}$ de largo; corola con 5 pétalos, amarillos, de 1.7-2.0 $\mathrm{cm}$ de largo, espatulados, el ápice acuminado, la base pubescente por ambos lados; androginóforo ca. $2.0 \mathrm{~mm}$ de largo, con 5 glándulas cuadrangulares, ca. $1.0 \mathrm{~mm}$ de largo, blanquecinas; el anillo menor a $5.0 \mathrm{~mm}$ de largo, ciliado; estambres 20; filamentos filiformes, ca $1.8 \mathrm{~cm}$; anteras ca. $1.0 \mathrm{~mm}$; ovario globoso de 1.0-1.5 mm de largo, muricado-hialino, trilocular con 2 óvulos por lóculo; estilo ca. $2.2 \mathrm{~cm}$ de largo; estigma trífido. Cápsula globosa, equinada, ca. $1.5 \mathrm{~cm}$ de largo, ca. $1.5 \mathrm{~cm}$ de ancho, el cuerpo ca. $6.0 \mathrm{~mm}$; espínulas ca. $4 \mathrm{~mm}$ de largo, aproximadamente 80, uncinadas, hialinas en el ápice. Semillas pardo-oscuras, piriformes, una por lóculo (ocasionalmente un lóculo con semilla abortiva), ca. 4.0 $\mathrm{mm}$ de largo, ca. $3.0 \mathrm{~mm}$ de ancho.

\section{Resumen taxonómico}

Paratipos. MÉXICO: Oaxaca; municipio de Totontepec; río Toro, $3 \mathrm{~km}$ al $\mathrm{S}$ de Totontepec, $1860 \mathrm{~m} \mathrm{snm}, 4$ septiembre 1986, E. Ramírez G. y P. Ramírez C. 441 (MEXU); Totontepec $\left(17^{\circ} 15^{\prime} \mathrm{N}, 96^{\circ} 02^{\prime} \mathrm{O}\right), 1900 \mathrm{~m} \mathrm{snm}$, 07 mayo 1990, J. Riviera R. y G. J. Martin 1477 (MEXU). Hábitat. Se desarrolla en bosque mesófilo de montaña, en altitudes de 1860 a $1900 \mathrm{~m}$.

Distribución. Restringida al estado de Oaxaca, hasta el momento se conoce sólo de la localidad tipo.

Fenología. Se colectó en floración y fructificación en los meses de mayo y septiembre.
Etimología. El epíteto específico honra al M. en C. Miguel Ángel Martínez Alfaro, promotor de la enseñanza de la botánica, especialmente de la etnobotánica, en el país, por su herencia personal y académica, al maestro y amigo.

Comentarios taxonómicos. Lay (1950) agrupa las especies del género en 3 series: Geniculatae, Stellatae y Uncinatae; T. matinezalfaroi se relaciona morfológicamente con $T$. coriacea y T. cucullata en la serie Geniculatae, la cual se integra con 17 especies con botones florales oblongos u oblongoideos, y espínulas del fruto con el ápice recto o ligeramente deflexo.

Triumfetta martinezalfaroi, T. coriacea y T. cucullata son similares en los sépalos en antesis que miden de 2-2.5 cm de largo, cuerpo del fruto maduro de 4-10 mm de diámetro y láminas de las hojas de $11-15 \mathrm{~cm}$ de largo con margen con prominentes glándulas basales. Difiere $T$. martinezalfaroi de estas especies en la forma de los sépalos filiformes y tamaño del apéndice (ca. $2 \mathrm{~mm}$ ), en los pétalos espatulados, en el número de estambres (20), en el estigma (trilobado), en el número de espínulas del fruto (aprox. 80), así como en el largo y ancho de la lámina de la hoja (2.5-8.0 y 1.0-4.0 respectivamente), en el ápice caudado y en la base (cordada) de la lámina (véase Cuadro 1).

En cuanto a la distribución conocida de las 3 especies, T. coriacea se restringe al suroeste de México, en los estados de Guerrero, Jalisco, Nayarit y Oaxaca; habita en bosques de Quercus, de Pinus, de Pinus-Quercus y tropical caducifolio, así como en vegetación secundaria, en altitudes de 565 a $1550 \mathrm{~m}$ (Gual, 1998); T. cucullata sólo se registra para el estado de Nayarit (una sola colecta conocida, sin registro del tipo de vegetación); al parecer, habita en bosques tropicales, caducifolio o subcaducifolio, en altitudes de 600 a $920 \mathrm{~m}$; T. martinezalfaroi, que hasta el momento sólo corresponde al estado de Oaxaca, habita el bosque mesófilo de montaña, en altitudes de 1860 a $1900 \mathrm{~m}$.

Clave sinóptica de identificación de las 2 especies afines y T. martinezalfaroi

1. Flores con sépalos filiformes y pétalos espatulados; estigma trífido; estambres 20; láminas de la hojas de 8.0 $\mathrm{cm}$ de largo, o menores, ovadas, el ápice caudado, la base cordada, el margen con 4 pares de dientes basales glandulares.

T. martinezalfaroi

$1^{\prime}$. Flores con sépalos elípticos u oblongos y pétalos obovados; estigma agudo no lobado o 5-lobado (no trífido); estambres 20-40; láminas de las hojas de $11 \mathrm{~cm}$ de largo, o mayores, ovadas a elípticas, el ápice acuminado o agudo, la base cuneada, redondeada u obtusa, el margen con 3-5 pares de dientes basales glandulares.

2. Flores con sépalos elípticos; estigma 5-lobado; estambres (35)40(45); láminas de las hojas ovadas a elípticas, de consistencia coriácea, ápice acuminado, la base cuneada o redondeada, el margen con 3-5 pares de dientes basales glandulares.

T. coriacea 2'. Flores con sépalos oblongos; estigma no lobado, agudo; estambres 20; láminas de las hojas elípticas, de consistencia papirácea, el ápice agudo, la base obtusa, el margen con 4 pares de dientes basales glandulares.

T. cucullata 
Cuadro 1. Comparación de caracteres distintivos entre Triumfetta martinezalfaroi y las especies afines

\begin{tabular}{|c|c|c|c|}
\hline Estructura/Carácter & T. martinezalfaroi & T. coriacea & T. cucullata \\
\hline \multicolumn{4}{|l|}{ Hoja } \\
\hline forma & $\begin{array}{l}\text { ovada, algunas ligeramente } \\
\text { trilobadas }\end{array}$ & $\begin{array}{l}\text { ampliamente ovada a elíptica, a } \\
\text { trilobadas }\end{array}$ & elíptica \\
\hline tamaño & $\begin{array}{l}2.5-8.0 \mathrm{~cm} \text { largo; } 1.0-4.0 \mathrm{~cm} \text { ancho } \\
\text { acuminado }\end{array}$ & $\begin{array}{l}11-14 \mathrm{~cm} \text { largo; } 8-12 \mathrm{~cm} \text { ancho } \\
\text { acuminado }\end{array}$ & $\begin{array}{l}13-15 \mathrm{~cm} \text { largo; } 4.0-5.0 \mathrm{~cm} \text { ancho } \\
\text { agudo }\end{array}$ \\
\hline \multirow[t]{2}{*}{$\begin{array}{l}\text { ápice } \\
\text { base }\end{array}$} & cordada con 4 pares de glándulas & $\begin{array}{l}\text { cuneada o redondeada con 3-5 } \\
\text { pares de glándulas }\end{array}$ & $\begin{array}{l}\text { obtusa con } 4 \text { pares de glándulas } \\
\text { evidentes a simple vista }\end{array}$ \\
\hline & $1.0-1.8 \mathrm{~cm}$ de largo & $4.0-6.0 \mathrm{~cm}$ de largo & $1.0-1.5 \mathrm{~cm}$ de largo \\
\hline \multicolumn{4}{|l|}{ pecíolo } \\
\hline \multicolumn{4}{|l|}{ Flor } \\
\hline largo & $2.7 \mathrm{~cm}$ & $2.2 \mathrm{~cm}$ & $2.2-2.4 \mathrm{~cm}$ \\
\hline pedicelo & ca. $1.0 \mathrm{~cm}$ de largo & $0.2-0.4 \mathrm{~cm}$ de largo & $0.3-0.5 \mathrm{~cm}$ de largo \\
\hline sépalo & filiforme, ca. $2 \cdot 0-2-2 \mathrm{~cm}$ de largo & elíptico, $2.2-2.4 \mathrm{~cm}$ de largo & oblongo, $2.2-2.5 \mathrm{~cm}$ de largo \\
\hline ápice & $\begin{array}{l}\text { acuminado, apéndice ca. } 2.0 \mathrm{~mm} \\
\text { de largo }\end{array}$ & $\begin{array}{l}\text { poco evidente (negruzco en } \\
\text { ejemplares herborizados); } \\
\text { apéndice ca. } 0.5 \mathrm{~mm} \text { de largo }\end{array}$ & $\begin{array}{l}\text { poco evidente; apéndice } 0.5-1.0 \mathrm{~mm} \\
\text { de largo }\end{array}$ \\
\hline & espatulado, $1.7-2.0 \mathrm{~cm}$ de largo & obovado, $2.0-2.2 \mathrm{~cm}$ de largo & obovado, ca. $2.3 \mathrm{~cm}$ de largo \\
\hline nétalo & glándulas cuadrangulares & glándulas elípticas & glándulas cuadrangulares \\
\hline petalo & 20 & 40 & 20 \\
\hline androginóforo & 3 & 5 & desconocido \\
\hline $\begin{array}{l}\text { no. estambres } \\
\text { no. lóculos } \\
\text { estigma }\end{array}$ & trífido & 5-lobado & agudo (no lobado) \\
\hline \multicolumn{4}{|l|}{ Fruto } \\
\hline espínulas & aprox. 80 , ca. $4 \mathrm{~mm}$ de largo & aprox. 200 , ca. $1 \mathrm{~mm}$ de largo & $\begin{array}{l}\text { aprox. } 50 \text { (con base a las descritas } \\
\text { en el ovario) }\end{array}$ \\
\hline cuerpo & ca. $0.6 \mathrm{~cm}$ & ca. $1.0 \mathrm{~cm}$ & desconocido \\
\hline
\end{tabular}

\section{Agradecimientos}

La primera autora agradece a la Dra. Nelly Diego P. y al M. en C. Rafael Torres Colín, por el apoyo crítico que ha permitido una retroalimentación continua a lo largo de varios años; así mismo, nuestro agradecimiento a la Biól. Laura Padilla por la elaboración profesional de la ilustración que acompaña este manuscrito.

\section{Literatura citada}

Cronquist, A. 1981. An integrated system of classification of flowering plants. Columbia University Press. New York. $1262 \mathrm{p}$.

Fryxell, P. A. 1998. A synopsis of the neotropical species of Triumfetta. In Diversity and taxonomy of tropical flowering plants, P. Mathew y M. Sivadasan (eds.) Mentor, Calicut. $330 \mathrm{p}$.

Gual, D. M. 1998. La familia Tiliaceae Juss., en el estado de Guerrero, México. Tesis, Maestría (biología vegetal) Facultad de Ciencias, Universidad Nacional Autónoma de México, México, D. F. 170 p.

Gual, D. M. 2011. La familia Tiliaceae. In Diversidad florística de Oaxaca: de musgos a angiospermas, A. García-Mendoza y J. A. Meave (eds.). Instituto de Biología, UNAM-Comisión Nacional para el Conocimiento y Uso de la Biodiversidad. México, D.F. 352 p.

Heywood, V. H. 1993. Las plantas con flores. Reverté, Barcelona. $332 \mathrm{p}$.

Lay, K. K. 1950. The American species of Triumfetta L. Annals of the Missouri Botanical Garden 37:315-395.

Mabberley, D. L. 2008. The plant-book. A portable dictionary of the higher plants. Cambridge University Press, 707 p. 